Article

\title{
An Improved Manufacturing Approach for Discrete Silicon Microneedle Arrays with Tunable Height-Pitch Ratio
}

\author{
Renxin Wang ${ }^{1,3, *}$, Wei Wang ${ }^{2}$ and Zhihong $\mathrm{Li}^{2, *}$ \\ 1 Science and Technology on Electronic Test \& Measurement Laboratory, North University of China, \\ Taiyuan 030051, China \\ 2 National Key Laboratory of Science and Technology on Micro/Nano Fabrication, \\ Institute of Microelectronics, Peking University, Beijing 100871, China; wei_w77@163.com \\ 3 Key Laboratory of Instrumentation Science \& Dynamic Measurement, Ministry of Education, \\ North University of China, Taiyuan 030051, China \\ * Correspondence: wangrenxin@nuc.edu.cn (R.W.); zhhli@pku.edu.cn (Z.L.); \\ Tel.: +86-351-392-0350 (R.W.); +86-10-6276-6581 (Z.L.) \\ Academic Editor: Stefano Mariani \\ Received: 12 August 2016; Accepted: 18 September 2016; Published: 9 October 2016
}

\begin{abstract}
Silicon microneedle arrays (MNAs) have been widely studied due to their potential in various transdermal applications. However, discrete MNAs, as a preferred choice to fabricate flexible penetrating devices that could adapt curved and elastic tissue, are rarely reported. Furthermore, the reported discrete MNAs have disadvantages lying in uniformity and height-pitch ratio. Therefore, an improved technique is developed to manufacture discrete MNA with tunable height-pitch ratio, which involves $\mathrm{KOH}$-dicing- $\mathrm{KOH}$ process. The detailed process is sketched and simulated to illustrate the formation of microneedles. Furthermore, the undercutting of convex mask in two $\mathrm{KOH}$ etching steps are mathematically analyzed, in order to reveal the relationship between etching depth and mask dimension. Subsequently, fabrication results demonstrate $\mathrm{KOH}$-dicing-KOH process. $\{321\}$ facet is figured out as the surface of octagonal pyramid microneedle. MNAs with diverse height and pitch are also presented to identify the versatility of this approach. At last, the metallization is realized via successive electroplating.
\end{abstract}

Keywords: discrete; microneedle; $\mathrm{KOH}$ etching; octagonal pyramid

\section{Introduction}

Recently, microneedle arrays (MNAs) draw more and more attention due to their great prospective in various applications such as transdermal electroporation [1], transdermal drug delivery [2], dry biopotential electrodes [3] and penetrating neural electrodes [4]. Flexible penetrating electrodes are preferred to adapt to curved and elastic tissue [4]. The contradiction is that penetration requires rigid microneedles whereas flexible substrates are also needed. Hence, discrete MNAs, which means the microneedles are different from the substrate in terms of their materials, are needed to fabricate this kind of flexible penetrating electrode via a transferring method. Diverse MNAs utilizing versatile processes, materials and shapes have been proposed, as shown in Table 1. Biodegradable materials such as polylactic acid (PLA) [5], poly-lactic-co-glycolic acid (PLGA) [6], polycaprolactone (PCL) [7], interferon $\alpha$ and polyvinyl alcohol (PVA) [8], sugar glass [9] and non-biodegradable polymer SU-8 [10] have been applied in molding-based fabrication of MNAs. The substrate and microneedles are usually made of the same material used in the molding process, otherwise the adherence between substrate and microneedle is too weak to maintain the MNA. Ren developed PLGA-based and Ti/Au-coated hill-like MNAs fabricated by thermal drawing for bio-signal monitoring [3]. 
The backside inadequate exposure technique was introduced to form SU-8 MNAs [11]. The electron discharge machining (EDM) method is presented to manufacture stainless steel MNAs [12]. These approaches could be considered as reductive manufacturing of the substrate. Hence, these MNAs have poor/fair discreteness, meaning that the microneedles could not be separated with the substrate in terms of material. Electrochemical etching titanium and microneedle insertion are performed to assemble titanium MNAs [13], which possess discrete microneedles but offer poor mass production possibilities.

On the other hand, silicon is widely used in fabricating MNAs due to its versatile tailoring process and high tensile strength, compared with other microneedle materials [14]. HNA (a mixture of $\mathrm{HNO}_{3}$, $\mathrm{HF}$ and HOAc) etching could be applied on silicon pillars via deep reactive ion etching (DRIE) or dicing in order to sharpen pillars until microneedles are formed $[2,15,16]$. However, HNA solution is so corrosive that heterogeneous substrates would be dramatically etched. Consequently, homogeneous silicon substrates are commonly adopted. Self-stabilized diamond-shaped microneedle formation via 2 stage etching was demonstrated [17]. Its base is very narrow and might be not strong enough to stand alone on a non-rigid heterogeneous substrate. A kind of discrete nipple-shaped microneedle prepared via dry etching was proposed, yet its uniformity is fair [4]. An octagonal pyramid silicon MNA was obtained via one stage $\mathrm{KOH}$ etching, which provided discrete and uniform microneedles. However, the ratio of height to pitch is very low (only 0.25 ), which is equivalent to density as the height is certain. As a matter of fact, it would reach a ceiling limit of about 0.46 according to the analysis of Section 3 (Equation (5)). Therefore, an alternate method is proposed in order to fabricate discrete MNA with tunable height-pitch ratios, which involves a $\mathrm{KOH}$-dicing- $\mathrm{KOH}$ process. 
Table 1. Diverse microneedle arrays.

\begin{tabular}{|c|c|c|c|c|c|c|}
\hline Source & Process & Material & Shape & Uniformity $^{a}$ & Discreteness $^{b}$ & Ratio of Height to Pitch \\
\hline Kim [5] & Replication and curved deformation & Biodegradable polylactic acid (PLA) & Cone & fair & poor & $350 / 950=0.37$ \\
\hline $\mathrm{Tu}[6]$ & $\mathrm{CO}_{2}$ laser ablation and polymer molding & poly-lactic-co-glycolic acid (PLGA) & Cone & fair & poor & $1179 / 500=2.36$ \\
\hline Keum [7] & Polymer molding & Polycarprolactone (PCL) & Cone & fair & poor & $700 / 900=0.78$ \\
\hline Kusamori [8] & Micro-molding & Interferon $\alpha$, polyvinyl alcohol (PVA) & Cone & fair & poor & $800 / 900=0.89$ \\
\hline Martin [9] & Low temperature vacuum deposition micromoulding & biodegradable sugar glass & Octagonal pyramid & good & poor & $250 / 1000=0.25$ \\
\hline Arai [10] & Replica molding & SU-8 & candle-shaped & good & poor & $1000 / 830=1.20$ \\
\hline $\operatorname{Ren}[3]$ & Thermal drawing & PLGA & Hill-like & good & fair & $500 / 1000=0.5$ \\
\hline Stavrinidis [11] & Backside inadequate exposure & SU-8 & Cone & poor & fair & $500 / 650=0.77$ \\
\hline Vinayakumar [12] & Electron discharge machining (EDM) & stainless steel & Hollow truncated Cone & fair & poor & $300 / 500=0.6$ \\
\hline Tezuka [13] & Electrochemical etching and insertion & Titanium & Cone & fair & good & $800 / 2500=0.32$ \\
\hline Yoon [15] & DRIE + HNA & Silicon & Cone & good & fair & $380 / 340=1.12$ \\
\hline Li [16] & DRIE + HNA & silicon & Cone & good & fair & $150 / 200=0.75$ \\
\hline Deng [2] & Dicing + HNA & silicon & rectangular pyramid & good & fair & $200 / 90=2.22$ \\
\hline Lin [17] & 2 Stage etch & Silicon & self-stabilized diamond-shaped & good & fair & $250 / 200=1.25$ \\
\hline Wang [4] & Dry etch & Silicon & nipple-shaped & fair & good & $80 / 450=0.18$ \\
\hline O'Mahony [18] & One stage $\mathrm{KOH}$ & Silicon & Octagonal pyramid & good & good & $300 / 1200=0.25$ \\
\hline This work & $\mathrm{KOH}-$ dicing-KOH & Silicon & Octagonal pyramid & good & good & Bigger than 0.56 , up to 2.65 \\
\hline
\end{tabular}

a The uniformity degree is judged from the reported figures, which is divided into three ranks. Higher rank means the profile and height of microneedles are more identical. ${ }^{b}$ The discreteness degree is judged from the fabrication process. The more possible the microneedle and substrate are made of different material, the higher rank it would be. 


\section{Fabrication Process}

$\mathrm{N}(100)$ silicon wafer with resistivity of $2 \sim 4 \Omega \cdot \mathrm{cm}$ is adopted as target object and a $\mathrm{KOH}$ etching process is kept in the condition of $30 \%$ concentration and $80^{\circ} \mathrm{C}$ temperature when mechanical agitation is applied. The fabrication process mainly consists of three steps: first $\mathrm{KOH}$ etching, dicing and second $\mathrm{KOH}$ etching. Specifically, the process is started from bonding a silicon wafer to glass, with patterned $\mathrm{Si}_{3} \mathrm{~N}_{4}$ as $\mathrm{KOH}$ mask composing of square and strip. Then, first $\mathrm{KOH}$ etching is performed to thin down the bulk silicon. The wafer is diced along the middle line of two adjacent square masks.

Dicing depth is well designed to make sure silicon with a certain thickness is retained. Silicon pillars with cross-like mask are formed. Eventually, second $\mathrm{KOH}$ etching is brought about. Owing to $\mathrm{KOH}$ undercutting of the convex mask corner, the silicon pillar would be etched along the facet with fast etching rate and finally silicon needles come into being after the cross-like mask is thoroughly undercut. It should be pointed out that the retained silicon during the dicing process is also etched just right, to obtain discrete silicon MNAs.

Here, $\mathrm{KOH}$-dicing-KOH process is simulated via Anisotropic Crystalline Etching Software (ACES). It should be noted that there is no model for the dicing process in ACES. The simulation of dicing is replaced with that of deep reactive ion etching (DRIE). The simulation results are illustrated in Figure 1: (a) silicon pillars are formed after first $\mathrm{KOH}$ etching and dicing; (b) Second $\mathrm{KOH}$ etching is started and the strips disappeared; (c) as the etching process goes on, the square mask begins to be undercut; (d) finally, the mask is thoroughly undercut and the octagonal pyramid-shaped microneedle comes out.

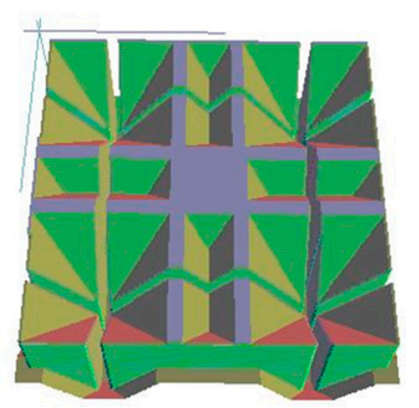

(a) First $\mathrm{KOH}$ etching and dicing

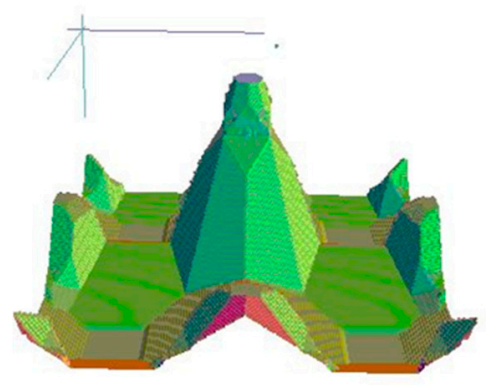

(c) Mediate process of second $\mathrm{KOH}$ etching

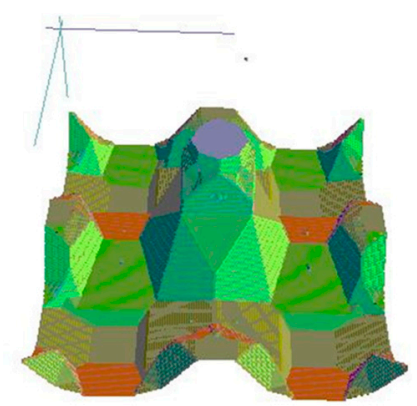

(b) At the beginning of second $\mathrm{KOH}$ etching

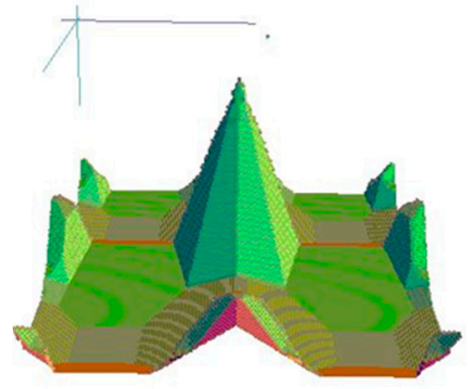

(d) Forming octagonal

pyramid-shaped microneedle

Figure 1. Simulation of second $\mathrm{KOH}$ etching.

\section{Mathematical Model}

Two KOH etching processes are mathematically concerned. Generally, undercutting happens beneath convex corner mask and along the inclining facet with fast etching rate. For $\mathrm{KOH}$ etching with $30 \%$ concentration and $80{ }^{\circ} \mathrm{C}$ temperature, the inclining facets are the cluster of $\{411\}$ facets. As the 
mask undercutting is prominently concerned, the evolution of $<410>$ crystal orientation is illustrated, which is the intersection line of $\{411\}$ facet and $\{100\}$ facet. The analyses could be divided into two parts.

\subsection{First $\mathrm{KOH}$ Etching}

First $\mathrm{KOH}$ etching starting from concentration strip mask is analyzed, as in Figure 2 . Width of strip is $w$, angle of $\langle 410\rangle$ and $<110>$ is $\alpha=31.0^{\circ}$, the distance from starting point to $<410>$ is $d_{C}$, the interception of inclining facet is $d$. It could be deduced that:

$$
\begin{gathered}
d_{c}=0.5 w \sin \alpha+d \cos \alpha-0.5 w \tan \alpha \leq d \leq 0.5 w \\
d_{c}=0.5 w \cos \alpha+d \sin \alpha d \geq 0.5 w
\end{gathered}
$$

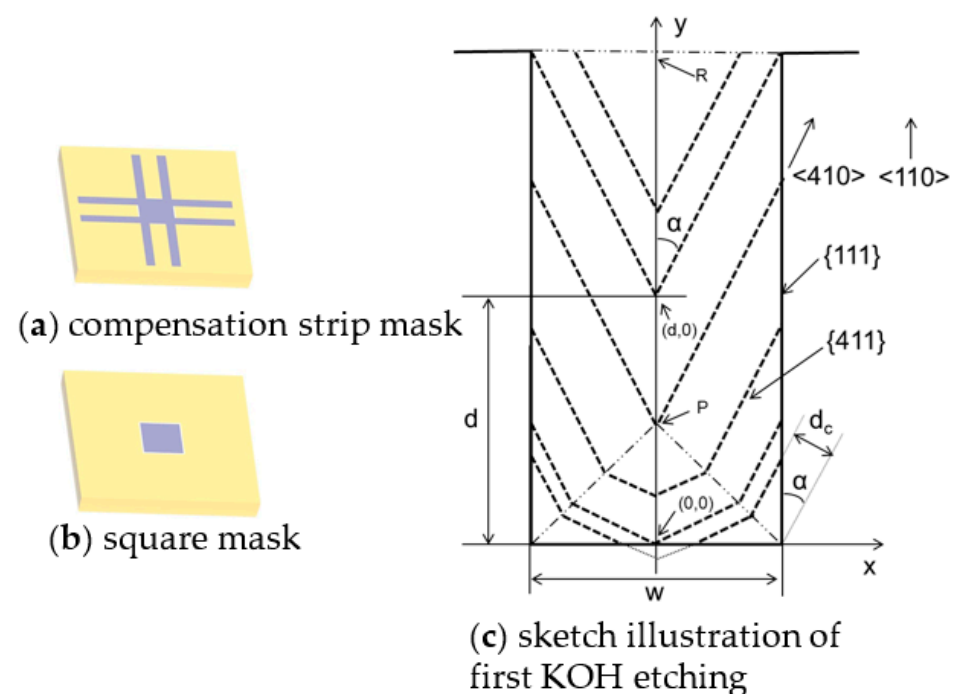

Figure 2. Sketch illustration of successive lateral etching beneath compensation strip. (First $\mathrm{KOH}$ etching).

The angle of $\{411\}$ and $\{100\}$ is $\beta=76.4^{\circ} . V_{\{411\}} / V_{\{100\}}=1.46$, where $V_{\{100\}}$ and $V_{\{411\}}$ are etching rates of $\{100\}$ and $\{411\}$ respectively. The evolution rate of $d_{C}$ is $V_{d_{c}}=V_{\{411\}} / \sin \beta$. Hence, the etching depth of $H$ could be figured out:

$$
H=\frac{d_{C}}{V_{d_{c}}} V_{\{100\}}=d_{C} \sin \beta \frac{V_{\{100\}}}{V_{\{411\}}}
$$

For concentration strip mask with width of $W_{c}$ and length of $L\left(L \geq 0.5 W_{C}\right)$, its maximum etching depth $H_{c m a x}$ could be derived from Equations (2) and (3):

$$
H_{C \max }=\left(0.5 W_{C} \cos \alpha+L \sin \alpha\right) \sin \beta \frac{V_{\{100\}}}{V_{\{411\}}}=0.3 W_{C}+0.36 L
$$

Similarly, square mask could be considered as two concentration strip mask, where etching starts from both side. For square mask with width of $W_{S}$, it would disappear when $d_{\text {max }}=0.5 W_{S}$. Maximum etching depth $H_{\text {Smax }}$ could be derived from Equations (1) and (3):

$$
H_{S \max }=\left(0.5 W_{S} \sin \alpha+d_{\max } \cos \alpha\right) \sin \beta \frac{V_{\{100\}}}{V_{\{411\}}}=0.46 W_{S}
$$




\subsection{Second $\mathrm{KOH}$ Etching}

As for second $\mathrm{KOH}$ etching, the situation is different, as shown in Figure 3. The mask consists of square mask with width of $W_{q}$ and concentration strip with $L$ length and $W_{q}$ width. The beginning facet for strip undercutting is $\{110\}$ created by dicing rather than $\{100\}$.

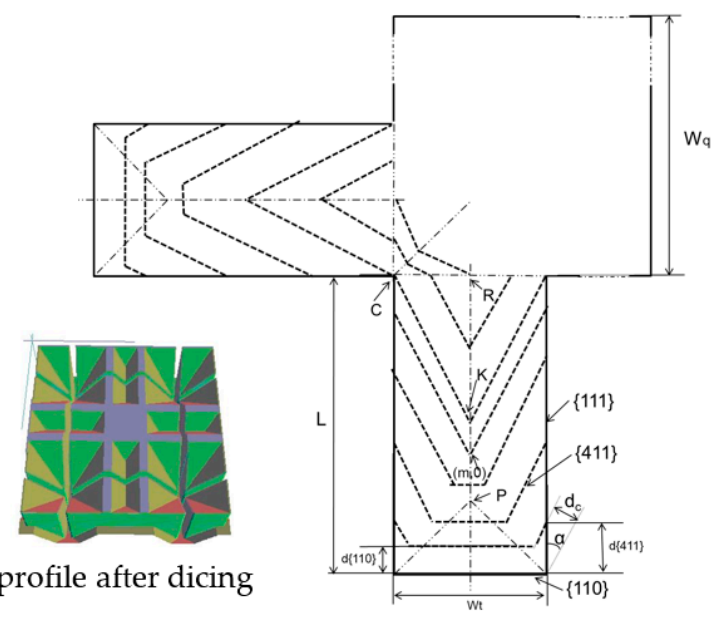

(b) sketch illustration of second $\mathrm{KOH}$ etching

Figure 3. Sketch illustration of successive lateral etching beneath compensation strip. (After dicing, second $\mathrm{KOH}$ etching).

Considering $V_{\{110\}}: V_{\{411\}}=1$, the etchings of $\{110\}$ and $\{411\}$ simultaneously proceed. When $\{411\}$ facet arrives point $C$, square mask starts to be undercut. The undercutting of strip goes on until $\{411\}$ facet arrives point $\mathrm{R}$. The overall etching depth along $\{100\}$ is $H_{j} . H_{c t}$ is the etching depth during the period when strip is undercut, $H_{s q}$ is the depth related to square mask, $H_{d}$ is the depth during the time from point $C$ to $R$ :

$$
H_{j}=H_{\mathrm{ct}}+H_{s q}-H_{d}=\left[0.5 W_{t} \cos \alpha+L \sin \alpha+0.5 W_{q}(\sin \alpha+\cos \alpha)-0.5 W_{t} \sin \alpha\right] \sin \beta \frac{V_{\{100\}}}{V_{\{111\}}}=0.13 W_{t}+0.36 L+0.46 W_{q}
$$

Considering $V_{\{110\}}: V_{\{411\}}=1$, the etchings of $\{110\}$ and $\{411\}$ simultaneously proceed. When $\{411\}$ facet arrives point $C$, square mask starts to be undercut. The undercutting of strip goes on until $\{411\}$ facet arrives point $\mathrm{R}$. The overall etching depth along $\{100\}$ is $H_{j} . H_{c t}$ is the etching depth during the period when strip is undercut, $H_{s q}$ is the depth related to square mask, $H_{d}$ is the depth during the time from point $C$ to $R$ :

$$
H_{j}=H_{\mathrm{ct}}+H_{s q}-H_{d}=\left[0.5 W_{t} \cos \alpha+L \sin \alpha+0.5 W_{q}(\sin \alpha+\cos \alpha)-0.5 W_{t} \sin \alpha\right] \sin \beta \frac{V_{\{100\}}}{V_{\{411\}}}=0.13 W_{t}+0.36 L+0.46 W_{q}
$$

\section{Results and Discussions}

\subsection{Fabrication Results}

Three kinds of MNAs with different height are demonstrated, which are $190 \mu \mathrm{m}, 270 \mu \mathrm{m}$, and $900 \mu \mathrm{m}$ respectively. Here, MNA with $190 \mu \mathrm{m}$ is taken as example to exhibit fabrication process. Figure 4 is obtained via scanning electron microscopy (SEM). Figure 4a demonstrates the silicon profile after $325 \mu \mathrm{m}$-thick silicon is firstly etched via $\mathrm{KOH}$ process. It could be noted that $75 \mu \mathrm{m}$-thick silicon is left in the margin region without $\mathrm{Si}_{3} \mathrm{~N}_{4}$ mask. The inset shows the compensation strip is about $200 \mu \mathrm{m}$ left, meaning that $900 \mu \mathrm{m}$-long strip is undercut. And $\{411\}$ facet could be observed beneath the strip, as well as other step-shaped facets. 


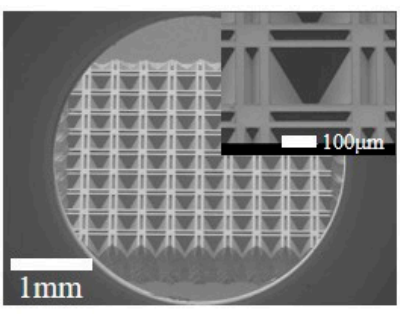

(a)After first $\mathrm{KOH}$

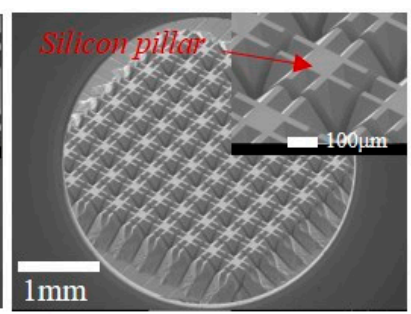

(b) Silicon pillar array

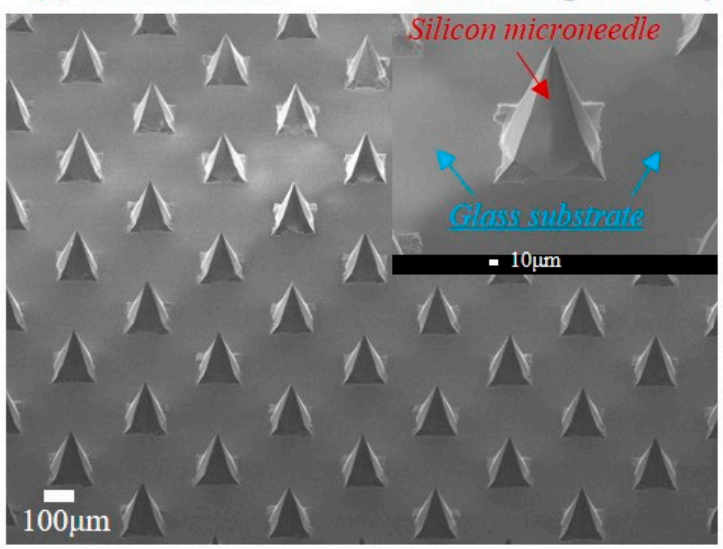

(c) Discrete silicon microneedle array

Figure 4. Fabrication process of microneedle array.

Then first $\mathrm{KOH}$ undercutting of the strip with width of $30 \mu \mathrm{m}$ and length of $900 \mu \mathrm{m}$ is considered. According to Equation (4), the corresponding etching depth $H_{c}=333 \mu \mathrm{m}$, which is in accordance with practical value $325 \mu \mathrm{m}$. Figure $4 \mathrm{~b}$ shows silicon pillar array with cross-like mask after dicing. The dimension of dicing groove is $40 \mu \mathrm{m}$-wide and $325 \mu \mathrm{m}$-deep, and the pitch is $340 \mu \mathrm{m}$. In order to form $9 \times 9$ array, 10 horizontal dicing and 10 vertical dicing are applied.

Figure 4c indicates discrete silicon MNA with height of $190 \mu \mathrm{m}$ is fabricated after second $\mathrm{KOH}$ etching. Here, the pitch of microneedle is $340 \mathrm{um}$. The inset demonstrates that the microneedle is an octagonal pyramid comprising of eight inclining facet. As a matter of fact, similar MNA could be manufactured via once $\mathrm{KOH}$ undercutting of square mask. However, to manufacture $190 \mu \mathrm{m}$-height MNA, $500 \mu \mathrm{m}$-wide square mask is required, which means the pitch of microneedle would be more than $500 \mu \mathrm{m}$. Hence, it could be noted that $\mathrm{KOH}$-dicing- $\mathrm{KOH}$ process is favorable to manufacture discrete silicon MNA with higher height-pitch ratio. According to Equation (6), when the dimension of cross-like mask is measured as: $W_{q}=92 \mu \mathrm{m}, L=92 \mu \mathrm{m}, W_{t}=22 \mu \mathrm{m}, H_{j}$ is figured out as $78 \mu \mathrm{m}$. In contrast, the etching depth in practice is $66 \mu \mathrm{m}$, which is smaller than theoretic value. The possible reasons may be the etching to $\mathrm{SiO}_{2}$ layer and inaccurate $V_{\{411\}}: V_{\{100\}}$.

\subsection{Facet of Octagonal Pyramid}

As mentioned before, the etching could be divided into three parts: the upper inclining facet under mask is $\{411\}$, the middle one is mainly along $\{110\}$ and lower one determines the final shape of microneedle, which is diverse in different condition. I. Silicon microneedles with $\{311\}$ facets are fabricated under conditions of $80{ }^{\circ} \mathrm{C}$ and $40 \% \mathrm{KOH}$ [19] as well as under conditions of $70{ }^{\circ} \mathrm{C}$ and $34 \% \mathrm{KOH}$ [20]. Dizon proposed a fabrication method to form $\{411\}$-facet microneedles in condition of $83{ }^{\circ} \mathrm{C}$ and $33 \% \mathrm{KOH}$ [21]. Wilke reported $\{321\}$-facet microneedles were realized under conditions of $79^{\circ} \mathrm{C}$ and $29 \% \mathrm{KOH}$ [22], which is very close to the conditions used in this paper. The angles measured from a top view (Figure 5a) and lateral view (Figure 5b,c) are compared with those of a 
theoretical $\{321\}$-facet pyramid, as shown in Table 2 . Ultimately, the $\{321\}$ facet is verified as the surface of octagonal pyramid microneedle.

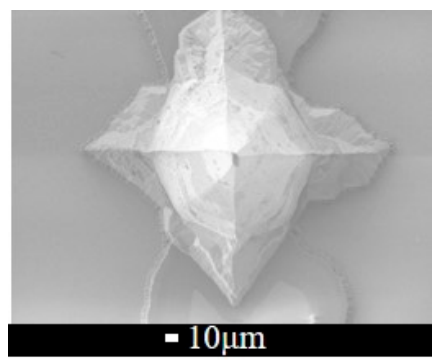

(a) Top view

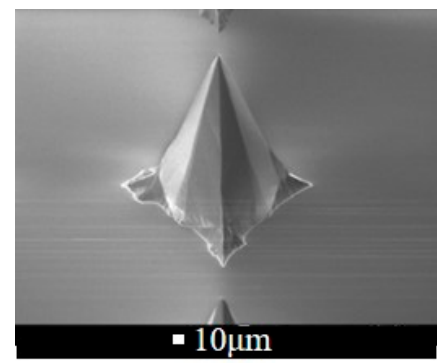

(b) Lateral view from $<110>$

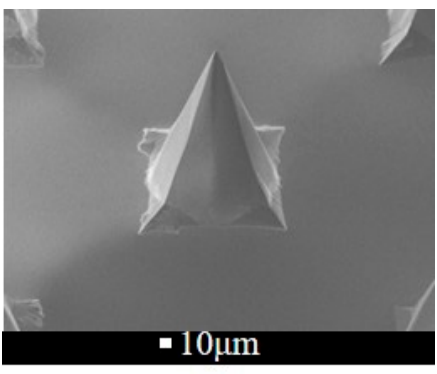

(c) Lateral view from $<100>$

Figure 5. Top view and lateral view SEMs of microneedles.

Table 2. Angles from different view.

\begin{tabular}{ccccc}
\hline & \multicolumn{2}{c}{ Top View } & \multicolumn{2}{c}{ Lateral View } \\
\cline { 2 - 5 } & Internal Angle 1 $^{\mathbf{a}}$ & Internal Angle 2 $^{\mathbf{a}}$ & $\gamma_{\langle\mathbf{1 1 0 >}}{ }^{\mathbf{b}}$ & $\gamma_{\langle\mathbf{1 0 0}>}{ }^{\mathbf{b}}$ \\
\hline Calculated \{321\}-facet pyramid & $143.1^{\circ}$ & $126.9^{\circ}$ & $37.2^{\circ}$ & $36.7^{\circ}$ \\
Measure from SEM & $136.8^{\circ} \pm 5.4^{\circ}$ & $133.8^{\circ} \pm 3.8^{\circ}$ & $39.4^{\circ}$ & $37.8^{\circ}$ \\
\hline
\end{tabular}

a The internal angles could be measured directly from top view SEM. ${ }^{\mathbf{b}}$ The cone angles of pyramid observed from $<110>$ and $<100>$ are $\gamma_{<110>}$ and $\gamma_{<100>}$, respectively, which could be calculated from lateral view SEM. The angle between SEM probe and the wafer is $\psi$ (here is $45^{\circ}$ ), and the measured cone angles in SEM is $\theta$. Hence, $\gamma_{<110>}$ and $\gamma_{<100>}$ are determined by $\tan \frac{\gamma}{2}=\cos \psi \times \tan \frac{\theta}{2}$.

\subsection{MNAs with Diverse Height and Pitch}

Discrete MNAs with diverse height and pitch are also fabricated, as Figure 6 shows. MNAs with $270 \mu \mathrm{m}$-high and $420 \mu \mathrm{m}$-pitch are illustrated in Figure 6a, which accords with the aforementioned octagonal pyramid profile. After first $\mathrm{KOH}$ etching, $W_{c}=40 \mu \mathrm{m}, \mathrm{L}=880 \mu \mathrm{m}$, according to Equation (4), the corresponding etching depth $H_{c}=329 \mu \mathrm{m}$, which is in accordance with the practical value of $320 \mu \mathrm{m}$. According to Equation (6), when the dimension of cross-like mask is measured as: $W_{q}=143 \mu \mathrm{m}$, $L=106 \mu \mathrm{m}, W_{t}=24 \mu \mathrm{m}, H_{j}$ is figured out as $107 \mu \mathrm{m}$. In contrast, the etching depth in practice is $96 \mu \mathrm{m}$, meaning that the estimation error is about $10 \%$. The possible reasons may be the etching to $\mathrm{SiO}_{2}$ layer and inaccurate $V_{\{411\}}: V_{\{100\}}$, as mentioned before.
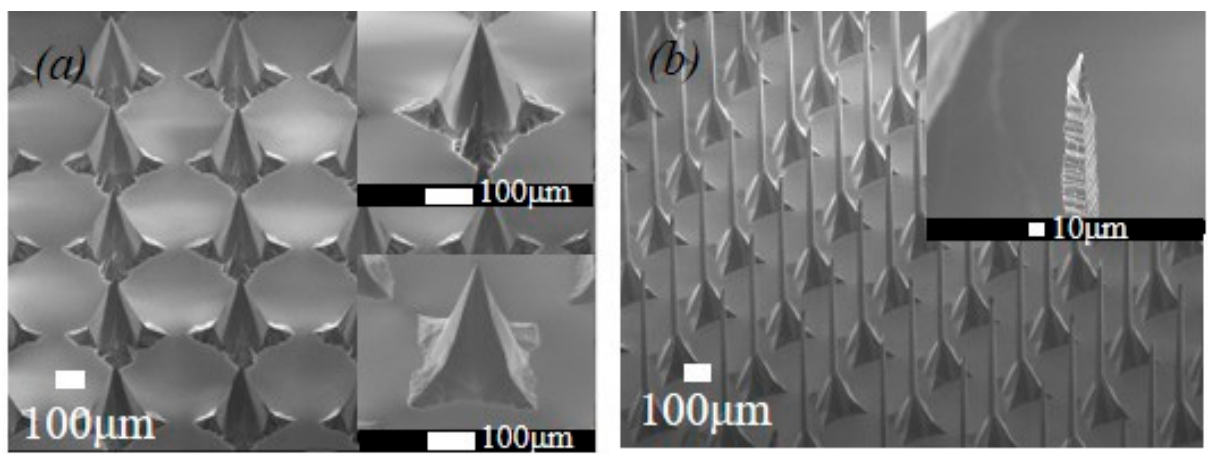

Figure 6. SEMs of Microneedle arrays with (a) $270 \mu \mathrm{m}$ height and $420 \mu \mathrm{m}$ pitch; (b) $900 \mu \mathrm{m}$ height and $340 \mu \mathrm{m}$ pitch.

Figure 6b shows a MNA with $900 \mu \mathrm{m}$-high and $340 \mu \mathrm{m}$-pitch, which consists of slender tips, straight pillars and pyramid bases. As a matter of fact, the evolution of this microneedle could 
be observed in simulation, as Figure 3 showed. The upper inclining facets under mask constitute slender tips, the middle ones along $\{110\}$ compose the straight pillars and the lower ones form the pyramidal base. It is obvious that this kind of high microneedle could not undergo the penetration force. Nevertheless, it could have potential in non-contact applications such as field emission.

\subsection{Metallization on MNAs}

'Metallization' means to deposit and pattern a metal on the MNA, which makes it possible for electrical applications. It should be noted that there is a gap between discrete silicon microneedles and glass substrates, as in Figure 7. The gap in the range of several micrometers is inevitably caused due to $\mathrm{KOH}$ etching of the glass. However, the gap is fatal for the metallization because the thickness of routine metal sputtering is about several hundred nanometers and too small to cover the gap. Hence, a probable solution via successive electroplating is proposed. Specially, $150 \mathrm{~nm} \mathrm{Cr} / \mathrm{Au}$ is sputtered and patterned on the wafer. The metals on microneedle and glass are separated (Figure 7a).

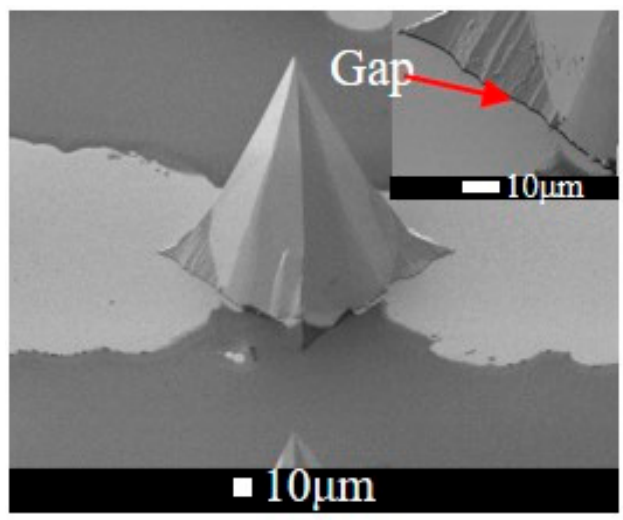

(a)

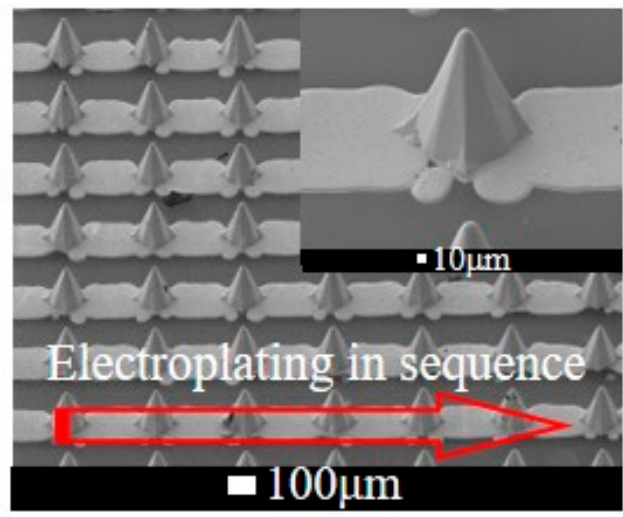

(b)

Figure 7. SEMs of microneedle arrays with (a) metal sputtering; (b) successive electroplating.

Subsequently, electroplating starts from one side. The No.1 microneedle would be electroplated when the thickness of the metal line reaches up to the edge of microneedle and fills the gap. Then, the metal on microneedle is thickened, leading to connecting with adjacent metal line. Therefore, electroplating goes on in sequence and finally all the microneedles on this line are electroplated (Figure 7b). In fact, the metal is apt to be electroplated thicker on the edge. As a consequence, the gap could be quickly filled.

\section{Conclusions}

In this paper, an improved $\mathrm{KOH}$-dicing- $\mathrm{KOH}$ process is proposed in order to fabricate discrete silicon MNAs with tunable height-pitch ratio. Compared with previously reported MNAs, their advantage lies in the discreteness and height-pitch ratio. Many efforts are made to demonstrate the formation of MNAs, including simulation, mathematical calculations and SEM experiments. In addition, the observed octagonal pyramids are confirmed to be composed of $\{321\}$ facets. Further experiments indicate it has potential to produce diverse MNAs for versatile applications. The problem existing in metallization is solved via successive electroplating, which makes it feasible for microneedle electrode applications. In conclusion, the fabrication and analysis of these MNAs are demonstrated. Further research on the applications of these MNAs will be carried out.

Acknowledgments: This work was supported by the National Natural Science Foundation of China (Grant No. 91323304 and Grant No. 61604134). The authors would like to thank the stuff in the National Key Laboratory of Science and Technology on Micro/Nano Fabrication in Peking University for their valuable assistance in fabrication process. 
Author Contributions: R. Wang and Z. Li designed the experiments and analyzed the data; R. Wang performed the experiments and wrote the paper; W. Wang provided experiment instruction.

Conflicts of Interest: The authors declare no conflict of interest.

\section{References}

1. Choi, S.-O.; Kim, Y.C.; Park, J.-H.; Hutcheson, J.; Gill, H.S.; Yoon, Y.-K.; Prausnitz, M.R.; Allen, M.G. An electrically active microneedle array for electroporation. Biomed. Microdevices 2009, 12, $263-273$. [CrossRef] [PubMed]

2. Deng, Y.; Chen, J.; Zhao, Y.; Yan, X.; Zhang, L.; Choy, K.; Hu, J.; Sant, H.J.; Gale, B.K.; Tang, T. Transdermal Delivery of siRNA through Microneedle Array. Sci. Rep. 2016, 6, 21422. [CrossRef] [PubMed]

3. Ren, L.; Jiang, Q.; Chen, K.; Chen, Z.; Pan, C.; Jiang, L. Fabrication of a Micro-Needle Array Electrode by Thermal Drawing for Bio-Signals Monitoring. Sensors 2016, 16, 908. [CrossRef] [PubMed]

4. Wang, R.; Zhao, W.; Wang, W.; Li, Z. A Flexible Microneedle Electrode Array With Solid Silicon Needles. J. Microelectromech. Syst. 2012, 21, 1084-1089. [CrossRef]

5. Kim, M.; Kim, T.; Kim, D.S.; Chung, W.K. Curved microneedle array-based sEMG electrode for robust long-term measurements and high selectivity. Sensors 2015, 15, 16265-16280. [CrossRef] [PubMed]

6. Tu, K.T.; Chung, C.K. Rapid prototyping of biodegradable microneedle arrays by integrating $\mathrm{CO}_{2}$ laser processing and polymer molding. J. Micromech. Microeng. 2016, 26, 065015. [CrossRef]

7. Keum, D.H.; Jung, H.S.; Wang, T.; Shin, M.H.; Kim, Y.E.; Kim, K.H.; Ahn, G.O.; Hahn, S.K. Microneedle Biosensor for Real-Time Electrical Detection of Nitric Oxide for in Situ Cancer Diagnosis During Endomicroscopy. Adv. Healthc. Mater. 2015, 4, 1153-1158. [CrossRef] [PubMed]

8. Kusamori, K.; Katsumi, H.; Sakai, R.; Hayashi, R.; Hirai, Y.; Tanaka, Y.; Hitomi, K.; Quan, Y.; Kamiyama, F.; Yamada, K.; et al. Development of a drug-coated microneedle array and its application for transdermal delivery of interferon alpha. Biofabrication 2016, 8, 015006. [CrossRef] [PubMed]

9. Martin, C.J.; Allender, C.J.; Brain, K.R.; Morrissey, A.; Birchall, J.C. Low temperature fabrication of biodegradable sugar glass microneedles for transdermal drug delivery applications. J. Control Release 2012, 158, 93-101. [CrossRef] [PubMed]

10. Arai, M.; Kudo, Y.; Miki, N. Polymer-based candle-shaped microneedle electrodes for electroencephalography on hairy skin on hairy skin. Jpn. J. Appl. Phys. 2016, 55, 06GP16. [CrossRef]

11. Stavrinidis, G.; Michelakis, K.; Kontomitrou, V.; Giannakakis, G.; Sevrisarianos, M.; Sevrisarianos, G.; Chaniotakis, N.; Alifragis, Y.; Konstantinidis, G. SU-8 microneedles based dry electrodes for Electroencephalogram. Microelectron. Eng. 2016, 159, 114-120. [CrossRef]

12. Vinayakumar, K.B.; Kulkarni, P.G.; Nayak, M.M.; Dinesh, N.S.; Hegde, G.M.; Ramachandra, S.G.; Rajanna, K. A hollow stainless steel microneedle array to deliver insulin to a diabetic rat. J. Micromech. Microeng. 2016, 26, 065013. [CrossRef]

13. Tezuka, M.; Kitamura, N.; Miki, N. Information transfer using wearable thin electrotactile displays with microneedle electrodes. Jpn. J. Appl. Phys. 2016, 55, 06GP15. [CrossRef]

14. Larraneta, E.; Lutton, R.E.M.; Woolfson, A.D.; Donnelly, R.F. Microneedle arrays as transdermal and intradermal drug delivery systems: Materials science, manufacture and commercial development. Mater. Sci. Eng. $R$ 2016, 104, 1-32. [CrossRef]

15. Yoon, Y.; Lee, G.S.; Yoo, K.; Lee, J.B. Fabrication of a microneedle/CNT hierarchical micro/nano surface electrochemical sensor and its in vitro glucose sensing characterization. Sensors 2013, 13, 16672-16681. [CrossRef] [PubMed]

16. Li, Z.; Li, Y.; Liu, M.; Cui, L.; Yu, Y. Microneedle Electrode Array for Electrical Impedance Myography to Characterize Neurogenic Myopathy. Ann. Biomed. Eng. 2016, 44, 1566-1575. [CrossRef] [PubMed]

17. Lin, C.; Ko, L.; Chiou, J.; Duann, J.; Huang, R.; Liang, S.; Chiu, T.; Jung, T. Noninvasive Neural Prostheses Using Mobile and Wireless EEG. Proc. IEEE 2008, 96, 1167-1183.

18. O’Mahony, C.; Pini, F.; Blake, A.; Webster, C.; O’Brien, J.; McCarthy, K.G. Microneedle-based electrodes with integrated through-silicon via for biopotential recording. Sens. Actuators A Phys. 2012, 186, 130-136. [CrossRef]

19. Chung, I.J.; Murfett, D.B.; Hariz, A.; Haskard, M.R. Fabrication of high aspect ratio silicon micro-tips for field emission devices. J. Mater. Sci. 1997, 32, 4999-5003. [CrossRef] 
20. Shikida, M.; Nanbara, K.; Koizumi, T.; Sasaki, H. A model explaining mask-corner undercut phenomena in anisotropic silicon etching: A saddle point in the etching-rate diagram. Sens. Actuators A. Phys. 2002, 98, 758-763. [CrossRef]

21. Dizon, R.; Member, S.; Han, H.; Russell, A.G.; Reed, M.L. An Ion Milling Pattem Transfer Technique for Fabrication of Three-Dimensional Micromechanical Structures. J. Microelectromech. Syst. 1993, 2, 151-159. [CrossRef]

22. Wilke, N.; Reed, M.L.; Morrissey, A. The evolution from convex corner undercut towards microneedle formation: Theory and experimental verification. J. Micromech. Microeng. 2006, 16, 808-814. [CrossRef]

(C) 2016 by the authors; licensee MDPI, Basel, Switzerland. This article is an open access article distributed under the terms and conditions of the Creative Commons Attribution (CC-BY) license (http://creativecommons.org/licenses/by/4.0/). 